it appeared that there was scope for closer liaison between the two specializations concerned, namely the radiochemical technology of the hot laboratory and the physico-biological technology of radio-protection. There was at least one suggestion that this matter might be the subject of a future symposium.

It was perhaps not surprising that on most matters considered at Grenoble, the conclusions of the experts from the various countries represented were similar. Indeed in many fields it was clear that standard methods were beginning to be adopted (particularly for non-destructive testing) and that this was leading to the adoption of standardized items of equipment in all laboratories. Participants generally welcomed this trend which doubtless owes its origins to previous intornational discussions which, if on a less ambitious scale, were none the loss the forerunners of the Grenoble Symposium.

The Proceedings of the Symposium, including all papers and discussions as woll as a directory of highactivity hot laboratories in opcration in OECD countries, will be published by ENEA towards the end of September.

\title{
MENDEL MEMORIAL BUILDING, HYNČICE
}

\begin{abstract}
$\mathrm{O}^{*}$ J June 13, the birthplace of Gregor Mendel at Hynčice, Czechoslovakia, was officially opened to the public and a memorial plaque unveiled to celebrate the occasion.

The house, built by Mendel's father on the site of a former wooden building, has been reconstructed, thanks to the efforts of the Regionel Department for the Preservation of Historical Monuments in Ostrava, the Distriet National Council, and tho District Museum in Nový Jičín. On the ground floor, the Moravian Museum of Brno has restored the former kitchen and the room where Mendel was born.

The arrangement of the memorial building was, to a great extent, determined by the rooms available. This necessitated dividing thom into two parts, representing, on one hand, Mendel's life aind, on the other, his scientific activities.

In the first part, Mondel's birth certificate is displayed in tho rooin where he was born in 1822. Other exhibits there record his genealogy, family background, and details of the schools where he obtained his basic education. There are also photographs and documents of the period, testifying to Mendel's entry into the Monastery of Old Brno, his teaching activities at the Brno Secondary School, and finally his election as A.bbot in I868. The final exhibits in this section include the obituary notice issued by the Monastery on the day of his death, and the photograph of the Monastery vault in the Central Cemetery in Brno, where he gained his final resting place.
\end{abstract}

The second part, which is aimed at acquainting the visitor with Mendel's work and its significance, particularly stresses his interest in natural science. It was this interest which led him, after his theological studies had been completed, to study at the University of Vienna.

Later he returned to Brno wherc for many years he performed his experiments on the heredity of peas. It was these, now classical experiments, which led to the formulation of his theory of dominant and recessive characters and its publication in 1865. His theory, how. ever, was not recognized until it was publicized by de Vries, Correns and Tschermak at the beginning of the present century. The final documents exhibited in this section indicate the great use which sciontific research workers throughout the world have made of Mendel's work.

The official opening of Mendel's birthplace aroused considerable interest among the general public, and at the coremony Dr. V. Orel, head of the Gregor Mendel Department of Geneties in the Moravian Museum in Brno, gave an inaugural address in which he briefly outlined Mendel's life and explained the significance of his work. He also recalled Mendel's close ties with his family and his native village.

The opening of this memorial building gave Hynčice the chance to inaugurate the official celebrations of the c nntenary of the publication of Mendel's classic paper, and in this way of paying honour to its most famous son.
Ludmila Marvanová

\section{POSITIONS OF THREE COSMIC X-RAY SOURCES IN SCORPIO AND SAGITTARIUS}

\author{
By G. CLARK, G. GARMIRE, M. ODA* and M. WADA $\dagger$ \\ Laboratory for Nuclear Science and Department of Physics, Massachusetts Institute of Technology \\ AND

\section{R. GIACCONI, H. GURSKY and J. R. WATERS \\ American Science and Engineering, Inc.}

\begin{abstract}
$\mathrm{W}$ E have determined the positions of throo cosmic $\mathrm{X}$-ray sources in the constellations of Scorpio and Sagittarius within uncertainty areas of $1 \cdot 2-3$ square degrees. Positions for these sources were reportod earlior by us at the Austin Conforonce on Relativistic Astrophysics on tho basis of a preliminary analysis of the same data ${ }^{1}$. One of these sources is $S \operatorname{co} X-1$, which was first dotected by Giacconi et al. in 1962 (ref. 2). (Our designations specify the constellation and the order of discovery, for example, ScoX-2 for second X-ray source in Scorpio.)
\end{abstract}

* On leave from the University of Tokyo.

$t$ On leave from the Institute of Physical and Chemical Research, Tokyo.
The other two, SgrX-I and ScoX-2, lie near the galactic plane in the complex of sources the existence of which was reported in a previous publication ${ }^{3}$. Wo have also located a probable fourth source to within $1^{\circ}$ of a segment of a great circle that is almost parallel to and about $4^{\circ}$ below tho galactic equator. The Kepler supernova remnant $S N 1604$ was scanned and no evidence of an X-ray source at its position was found.

We obtained the data with a rockot that was launched from White Sands, New Mexico, on October 26, 1964, at a sidereal time of $20 \mathrm{~h} 20 \mathrm{~m}$, and reached an apogee of $224 \mathrm{~km}$. Above the atmosphere the rocket spun around. 